\title{
THE ROLE OF SUCTION IN THE ADHESION OF LIMPETS
}

\author{
BY ANDREW M. SMITH \\ Department of Biology, CB no. 3280, Coker Hall, The University of North \\ Carolina, Chapel Hill, NC 27599-3280, USA
}

Accepted 16 July 1991

\begin{abstract}
Summary
Experiments were performed to determine the mechanism by which limpets attach to the substratum. Pressure measurements were made under the feet of three species of limpets as they were forcibly detached from the substratum. These measurements show that limpets actively decrease the pressure under their feet, and in almost every case this pressure decrease can account for all of their tenacity. The results are the same whether the pressure transducer is flush with the surface or connected to the surface via a tube. The tenacity of limpets is dependent on ambient pressure, as predicted for a suction mechanism. Leaks disrupt the attachment of limpets. Thus, for at least an hour after they have been moving, suction appears to be the primary attachment mechanism of limpets. Limpets using suction often have tenacities greater than $0.1 \mathrm{MN} \mathrm{m}^{-2}$, which corresponds to pressures under the foot lower than $0 \mathrm{MPa}$.

If limpets have more than a few hours to attach, approximately $30 \%$ of them form a different, stronger attachment that appears to be based on glue. These limpets remain stationary for extended periods. It is hypothesized that limpets in the field alternate between the use of suction and glue, depending on their need for mobility.
\end{abstract}

\section{Introduction}

It is commonly assumed that suction attachment mechanisms are unable to generate pressures lower than $0 \mathrm{MPa}$. At sea level, when a sucker decreases to $0 \mathrm{MPa}$ the pressure of the water it encloses, it creates a $0.1 \mathrm{MPa}(1 \mathrm{~atm})$ pressure differential from ambient. This pressure differential results in a tenacity, defined as the attachment force per unit area of the foot, of $0.1 \mathrm{MN} \mathrm{m}^{-2}$ $\left(1 \mathrm{MN} \mathrm{m}^{-2}=1 \mathrm{MPa}\right)$. Thus, the maximum tenacity at sea level of an animal using suction is believed to be $0.1 \mathrm{MN} \mathrm{m}^{-2}$. Whenever an animal's tenacity is greater than this, a suction attachment mechanism is considered to be ruled out (Yule and Crisp, 1983; Branch and Marsh, 1978; Grenon and Walker, 1981).

The assumption that suckers cannot generate pressures below $0 \mathrm{MPa}$, negative pressures, has been disproved recently. Smith (1991) has shown that octopus suckers generate negative pressures. Thus, one cannot automatically rule out a

Key words: suction, adhesion, limpets, pressure, Tectura scutum, Lottia gigantea, Lottia pelta. 
suction mechanism when an animal's tenacity exceeds $0.1 \mathrm{MN} \mathrm{m}^{-2}$ at sea level. This means that the prevalence of suction mechanisms in invertebrates may have been underestimated.

Limpets provide an example of a situation where the role of suction attachment may have been underestimated. Limpets routinely attach themselves to rocks with remarkable force (Aubin, 1892; Piéron, 1909; Menke, 1911; Wells, 1917; Loppens, 1922; Miller, 1974; Branch and Marsh, 1978; Grenon and Walker, 1981). Piéron (1909), Parker (1911) and Loppens (1922) all describe suction as the attachment mechanism. Branch and Marsh (1978) and Grenon and Walker (1981), however, conclude that limpet attachment cannot be due to suction because their tenacity exceeds 0.1 $\mathrm{MN} \mathrm{m}^{-2}$. Davis (1895), Menke (1911), Thomas (1948), Crisp (1973), Branch and Marsh (1978) and Grenon and Walker (1981) propose that adhesion results from tackiness of the pedal mucus. The pedal mucus is thought to act either as a viscoelastic glue or as a Stefan adhesive, where two surfaces are so close together that the viscosity of the intervening fluid resists their separation.

This study was designed to discriminate between the various mechanisms of attachment that have been proposed for limpets.

\section{Materials and methods}

\section{Experimental animals}

Specimens of Tectura scutum (Rathke) and Lottia digitalis (Rathke) were collected at Friday Harbor Marine Laboratory, Friday Harbor, Washington, USA. Specimens of Lottia gigantea Sowerby, Lottia pelta (Rathke) and 'Collisella' scabra (Gould) were supplied by Chuck Winkler Enterprises, San Pedro, California. Specimens of Crepidula fornicata Linnaeus and several chitons were obtained from the coast near Beaufort, North Carolina, USA. The nomenclature of the limpets used in this study follows that of Lindberg (1986). Limpets were kept in a chilled, recirculating seawater system at Chapel Hill, North Carolina, USA. They survived for over 2 months in this system.

\section{The effect of leaks on limpet attachment}

Animals were allowed to adhere to clear, smooth acrylic sheets (Lucite). Small holes $(0.5 \mathrm{~mm}$ in diameter) had been drilled in areas of these sheets. After $30 \mathrm{~min}$ or more, the limpets' tenacity was tested by hand. Limpets that were firmly attached were forced to slide across the sheet until they passed over a hole. A constant force perpendicular to the substratum was applied throughout this test. If a limpet is using suction, a leak through the hole in the acrylic sheet will eliminate the pressure differential and thus the attachment force. This will not happen if the limpet is using glue or a Stefan adhesive (see Discussion).

\section{Force measurements}

Force measurements were made with the apparatus shown in Fig. 1. Clear acrylic blocks were shaped to fit each limpet's shell. The periostracum of the shell 


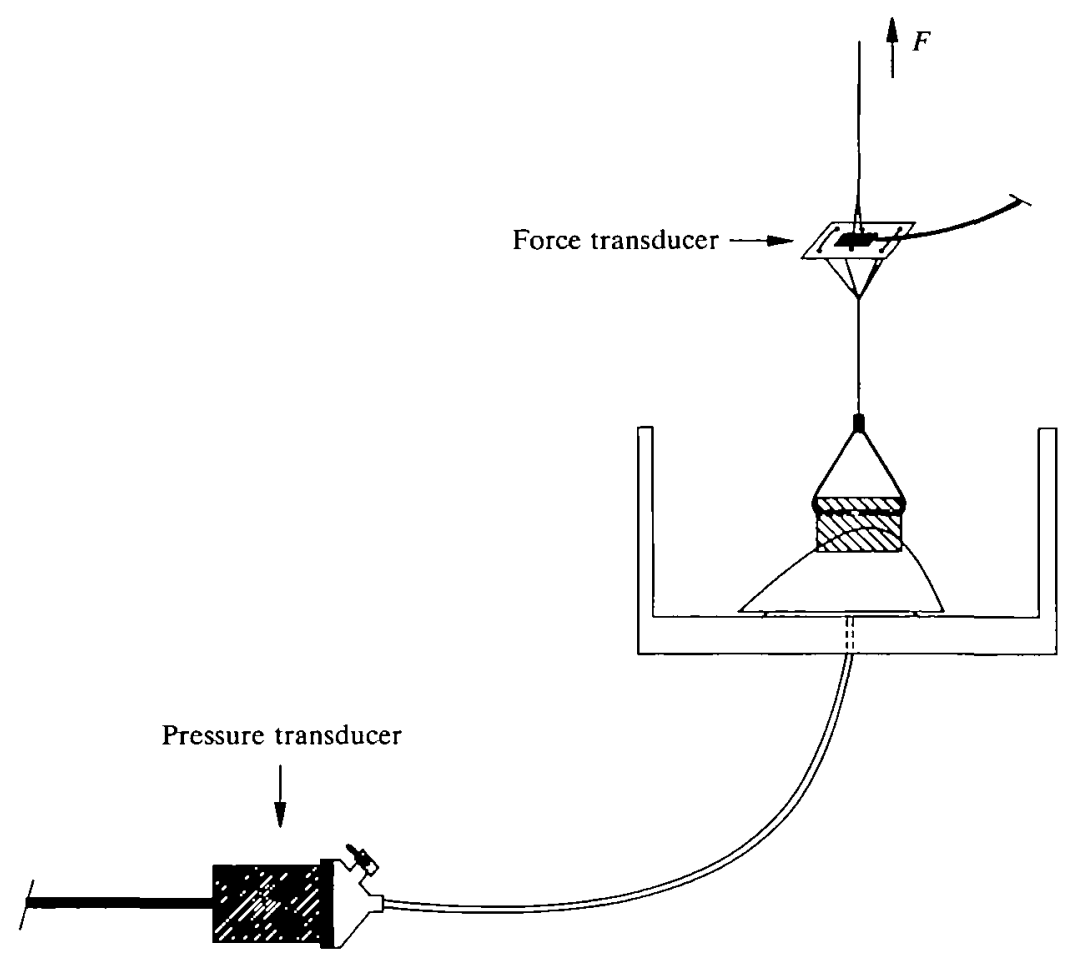

Fig. 1. Schematic diagram of the apparatus used for simultaneous measurements of the force required to detach limpets from the substratum and the pressure under their feet. $F$, force.

was ground off, the shell surface was cleaned with a cotton swab dipped in acetone, and Devcon 2-ton epoxy was used to glue the acrylic block to the clean surface. A hole was drilled through the acrylic block, so that a metal clip could be attached to the limpet. This metal clip was tied to $100 \mathrm{lb}(445 \mathrm{~N})$ test monofilament fishing line. A $4 \mathrm{~cm}^{2}$ copper sheet was attached in series with the monofilament so that the sheet would be deformed by three-point loading, and a strain gauge was bonded to the copper sheet. The strain gauge was wired to a Wheatstone bridge circuit and amplifier and the output was recorded on a Gould Electronics Brush 220 chart recorder. Calibrations were carried out by suspending containers of water from the metal clip. The values obtained from the regression equation for the calibration curve differed on average by $\pm 6 \%$ from the actual forces determined by the volume and density of the water, over a range from 0.05 to $2.5 \mathrm{~kg}$.

The tenacities of specimens of $T$. scutum were measured on the glass and painted walls of the aquarium and also on acrylic sheets. The purpose of these measurements was to determine the maximum tenacity that limpets can achieve using suction alone. The force of attachment was measured after sliding the limpet a few centimetres across the smooth surface. Presumably, this breaks any solid 
attachments that might be present. The limpet was then restrained so that it could only detach perpendicular to the test surface without further movement parallel to the surface. For each force measurement, the area of the limpet's foot attached to the glass aquarium wall was measured with calipers. Area was estimated by assuming that the outline of the foot is elliptical and measuring the major and minor axes. This measurement of area was corrected for the distortion of the intervening glass. The correction was determined by measuring the aperture of several limpet shells directly and then remeasuring them through the glass. The force at which the limpet's attachment failed was divided by the corrected area to give tenacity.

The ventral surfaces of the feet of $L$. pelta and $L$. gigantea were filmed with a JVC VHS hand-held recorder (VideoMovie) or a Magnavox Super VHS recorder (Video Escort) while the limpets were detached from a glass surface. Tenacity was measured simultaneously in 38 of the trials.

\section{Pressure measurements}

The pressures under the feet of $T$. scutum and $L$. gigantea were measured using a Gould-Statham P-23 ID pressure transducer (hereafter referred to as the Gould transducer) (Fig. 1). The limpets were placed on a walled platform designed to keep them centred over a pore. This pore transmitted pressure to the transducer via $0.7 \mathrm{~mm}$ diameter (i.d.) polyethylene tubing. With this apparatus, it was possible to observe the change in pressures as limpets were slid over the hole, irritated so that they clamped down, and slowly pulled off the surface. It was also possible to measure simultaneously pressure and tenacity, and thus to test whether the pressure differential accounts for all of the tenacity. In these trials, the limpets were allowed approximately $30 \mathrm{~min}$ to attach to the platform.

The Gould transducer was calibrated for pressures generated by a vacuum pump ranging from 0.1 to $0 \mathrm{MPa}$. The regression equation of the calibration curve predicts pressures that have an average $2 \%$ error using the actual pressures measured by a Bourdon vacuum gauge as a standard. Although this apparatus can measure pressures below ambient, its hydrophobic connecting surfaces nucleate cavitation at $0 \mathrm{MPa}$. Thus, this transducer limited limpets to a maximum pressure differential of $0.1 \mathrm{MPa}$ relative to ambient at sea level.

Pop tests were performed to determine the frequency response of the Gould transducer (Gabe, 1972). The undamped natural frequency was between 30 and $40 \mathrm{~Hz}$ and the damping factor was between 0.1 and 0.2 . This means that the transducer had an error of approximately $25 \%$ at $15-20 \mathrm{~Hz}$ (Gabe, 1972). This was sufficient for most measurements of pressure under limpet feet although, in some of the trials, the pressure change may have been sharp enough to lead to an overestimation of the pressure drop (see Discussion).

In separate experiments, the pressures under the feet of $T$. scutum and $L$. gigantea were measured using a Precision Measurement Co. miniature pressure transducer (model 060S) (hereafter referred to as the Precision transducer). Using Devcon 2-ton epoxy, the pressure transducer was glued into a depression on an 
acrylic platform similar to the one used with the Gould transducer. The $1.5 \mathrm{~mm}$ diameter transducer face was set flush with the surface, and the entire surface of the platform was coated with a thin layer of silicone rubber sealant. The flush mounting makes the transducer free from the error due to limitations of frequency response (Gabe, 1972). The silicone provides a uniform, solid, non-wettable surface, which limits the minimum possible pressure to $0 \mathrm{MPa}$ (Smith, 1991). Thus, the results should be comparable to the results from the Gould transducer. Calibration was performed as described by Smith (1991), and the average error of the device was $4 \%$. Tenacity measurements were also made simultaneously with pressure measurements.

An important difference between the two transducers is that, in addition to measuring decrease in hydrostatic pressure, the flush-mounted Precision transducer measures stress transmitted by any glue that may be present. The Gould transducer only measures decrease in hydrostatic pressure. Thus, comparison between the results from the two transducers under similar conditions allows estimation of the proportion of the tenacity resulting from glue.

\section{The effect of ambient pressure on limpet attachment}

The attachment force of an animal using glue should be independent of ambient pressure. In contrast, the theoretical maximum attachment force of an animal using suction depends on ambient pressure. This is because the attachment force of a sucker depends on the pressure differential it creates. The maximum pressure differential that a sucker can create equals the difference between ambient pressure and the minimum pressure that the water can sustain. Thus, if the minimum pressure that the water can sustain is constant, decreasing ambient pressure should decrease the attachment force of a sucker.

Measurements were performed in the following manner. Specimens of $L$. gigantea were allowed at least $30 \mathrm{~min}$ to attach to the Precision pressure transducer platform. Then the platform was placed in a bell jar with a stoppered top and a side outlet connected to a vacuum pump. The wires from the transducer left the bell jar through the rubber stopper. The limpets were detached using a steel wire that passed through the stopper such that it could slide easily up and down without breaking the seal. This wire was bent into an L-shape at its end so that it could fit through the hole in the acrylic block on the limpet. As the limpet was pulled up, the platform was restrained by the narrowing due to the curvature at the top of the jar. In these trials, the ambient pressure was maintained at a predetermined value between 0 and $0.1 \mathrm{MPa}$ for approximately $20 \mathrm{~s}$. The transducer's silicone coating set the minimum pressure that seawater could sustain at approximately $0 \mathrm{MPa}$. The force per unit area of the limpet's attachment was determined from the output of the Precision transducer, using ambient pressure as a baseline.

Control trials involved reducing the pressure to between 0.03 and $0.01 \mathrm{MPa}$ for approximately $20 \mathrm{~s}$, then returning to $0.1 \mathrm{MPa}$. The limpets were then immediately detached to see if the act of reducing pressure traumatized the limpets and weakened their attachment relative to trials without exposure to pressure change. 


\section{Results \\ Observations}

Limpets adhere well to acrylic and glass substrata. Even after sliding a short distance on a smooth surface they maintain much of their attachment force. If, however, they pass over a $0.5 \mathrm{~mm}$ diameter hole, their attachment fails immediately. This was true for all limpet species tested, including $L$. pelta, L. gigantea, L. digitalis, T. scutum, 'Collisella' scabra, the slipper shell Crepidula fornicata and several chitons. Before they have been moved, however, there is no evidence of whether leaks affect their tenacity.

If limpets are left undisturbed for prolonged periods, some of them form a noticeably different type of attachment. In $32 \%$ of individuals of $T$. scutum left undisturbed overnight $(N=116)$, the attachment was found to be stronger than usual. The attachment force of these limpets decreased sharply when they were moved from their original position. Also in these cases, a patch of semi-solid material remained stuck to the substratum where the limpet had been. These limpets were presumed to be using some form of glue. This type of attachment was typical of the slipper shell $C$. fornicata.

The other $68 \%$ of limpets that were undisturbed overnight were attached in a manner similar to limpets that are active or have been moved less than $2 \mathrm{~h}$ previously. They showed little decrease in tenacity after sliding a short distance and they left no solid residues where they were attached.

There is some evidence for the use of a glue in initial adhesion. L. gigantea and $L$. pelta attaching to the experimenter's finger attached first by the edge of their foot, which feels sticky. In some cases, limpets hung upside down using only a fraction of their foot area. When the entire rim was in contact and there were no gaps, the attachment force increased. The centre of the foot can similarly become sticky; in all cases this stickiness is not a constant property of the foot, but appears to be controlled by the limpet.

\section{Video analysis}

The video analysis shows that adhesive failure of limpets is predominantly due to leaks forming at the edge of the foot. A small part of the edge of the foot (estimated to be typically $1-5 \%$ of the circumference) is pulled in towards the centre, forming a $V$-shaped indentation in the outline of the margin. When this happens, the foot immediately detaches (Fig. 2A-C). In only three of 41 sequences, did the foot pull away with little change in shape, and in only one or two did it appear to peel away.

Fig. 2. Sequence of video frames of two different limpets being detached from the substratum. (A) The limpet's foot before applying force. (B) The foot immediately before detachment. Note the leak forming at the margin. (C) The next frame. The limpet has been pulled free of the substratum. (D) Another limpet before applying force. (E) The foot immediately before detachment. The sudden change in the appearance of the foot was interpreted to be due to the formation of a large gas bubble by cavitation. This disappeared as the limpet was pulled off in the next frame $(F)$. 

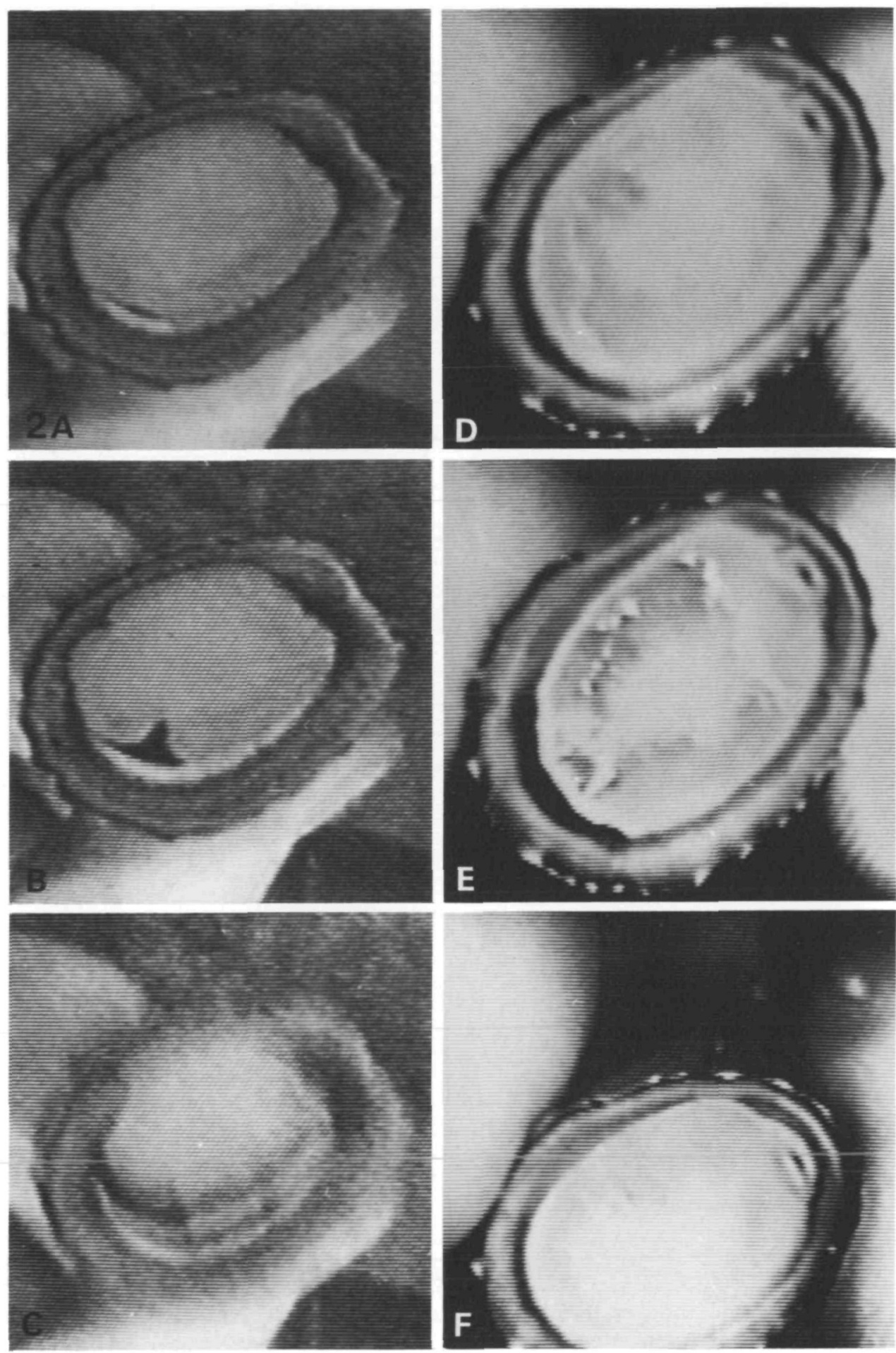
In four of the video sequences of detachment, a space suddenly appeared under the foot. This space was interpreted to be a large gas bubble caused by cavitation (Fig. 2D-F). The tenacities of the limpets in two of these sequences were 0.074 and $0.094 \mathrm{MN} \mathrm{m}^{-2}$, while the tenacities of the other two were unknown. In all four cases, a large area of the foot suddenly pulled away from the substratum and a glare, interpreted to be a gas/liquid interface, appeared (Fig. 2E). In three of these, the limpet's attachment failed in the following video frame. The other limpet, whose tenacity was $0.074 \mathrm{MN} \mathrm{m}^{-2}$, stayed attached with the space intact for a few more frames. After detachment, the glare disappeared and no gas bubbles were visible (Fig. 2F). This is to be expected, because as soon as the pressure equalizes, gas bubbles due to cavitation collapse.

\section{Force measurements}

The tenacity of T. scutum on glass, paint or Lucite, when glue was precluded by sliding the animals briefly, ranged from 0.06 to $0.23 \mathrm{MN} \mathrm{m}^{-2}$. The mean tenacity was $0.13 \pm 0.05 \mathrm{MN} \mathrm{m}^{-2}$ (mean \pm s.D., $N=26$ ). There were no significant differences between the mean tenacities on each surface ( $t$-test, $P>0.4$ in all comparisons). The regression equation for force versus area was $F=0.032 A^{0.85}(r=0.58)$, where $F$ is force and $A$ is area. In 13 of 26 measurements, the tenacity was greater than $0.1 \mathrm{MN} \mathrm{m}^{-2}$. Similarly, the tenacities of $L$. gigantea and $L$. pelta measured in other experiments often exceeded $0.1 \mathrm{MN} \mathrm{m}^{-2}$. If these limpets are using suction, as the evidence suggests, then they are consistently generating negative pressures in seawater.

Over the course of these experiments, the tenacity of individuals of $T$. scutum was measured without sliding them before the measurement. Some of these animals were clearly using glue, thus providing a rough estimate of the tenacity possible using glue. These values were typically between 0.1 and $0.2 \mathrm{MN} \mathrm{m}^{-2}$.

\section{Pressure measurements}

Limpets actively reduce the pressure under their feet (Fig. 3). The Gould transducer records a decrease in pressure whenever a limpet slides over the pore leading to the transducer. As the limpet slides off the hole, the pressure returns to ambient. Limpets that are attached over the hole generate a slight decrease in pressure that decreases further as they are irritated or forcibly detached. This decrease is sometimes smooth, but more often steplike (Fig. 3A). As the detaching force increases, the pressure stays constant until the detaching force approaches the force generated by the pressure differential. The pressure then decreases precipitously and immediately levels off again. This pattern occurred in 49 out of 77 trials with the Gould transducer.

In 16 of the 77 trials that were not steplike, detachment occurred so quickly that the recording of the pressure during detachment was a sharp spike. It should be noted that the minimum pressure that can be generated by pressing a finger hard up against the sensing pore and suddenly removing it was $0.092 \mathrm{MPa}(0.008 \mathrm{MPa}$ 
D

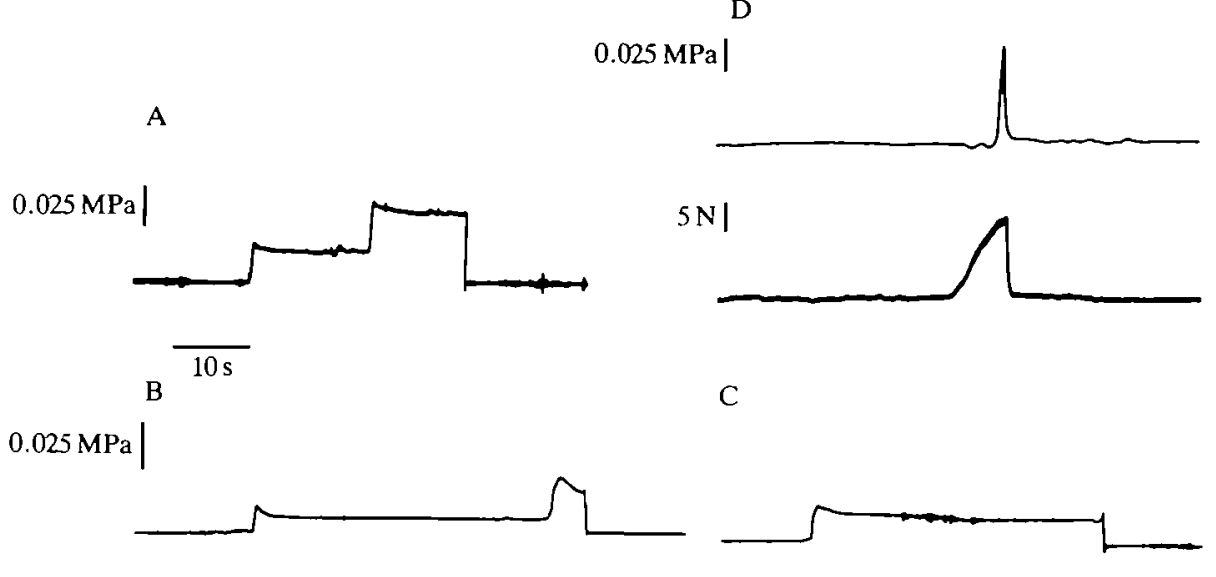

$5 \mathrm{NI}$

Fig. 3. Examples of pressure recordings from under limpet feet. (A) A sample pressure trace; the initial pressure decrease was caused by sliding the limpet over the transducer, the second decrease occurred when a weak effort was made to detach the limpet. (B,C) Pressure (top) and force (bottom) recordings made simultaneously for two different limpets. The initial decrease in pressure occurs as the metal clip is hooked onto the acrylic block on the limpet's back. In A-C the pressures were measured with the Gould transducer. (D) Simultaneous pressure (top) and force (bottom) measurements. Pressure was measured with the Precision transducer. The small increase in pressure while force was increasing was interpreted to be a result of the transducer being under the margin of the foot, which is pressed down to form a seal. As the foot lifts away, the transducer senses a sudden pressure decrease before the seal breaks.

below ambient). Thus, the spikes are probably not artefacts of the limpet suddenly breaking free.

Unlike the pressures measured by the Gould transducer, the pressure traces from the Precision transducer usually showed a more continuous decrease. The few steplike decreases were not as markedly stepped as those recorded by the Gould transducer. Some of the other pressure traces were intermediate between steplike and continuous.

\section{Simultaneous force and pressure measurements}

If the limpet's foot acts as a sucker, the pressure differential will determine the force per unit area of attachment. Therefore, at the moment the limpet's attachment fails, the absolute value of the pressure differential from ambient $(\Delta P)$ and the tenacity $(T)$ should be the same. Thus, the dimensionless ratio $\Delta P / T$ equals one. The pressure differential will actually be greater than the tenacity $(\Delta P / T>1)$ because the rim of the sucker must be pressed down to form a seal, and thus the pressure will act over a smaller area than that measured in determining tenacity. Also, owing to failure due to leaks, the limpet may detach before the 


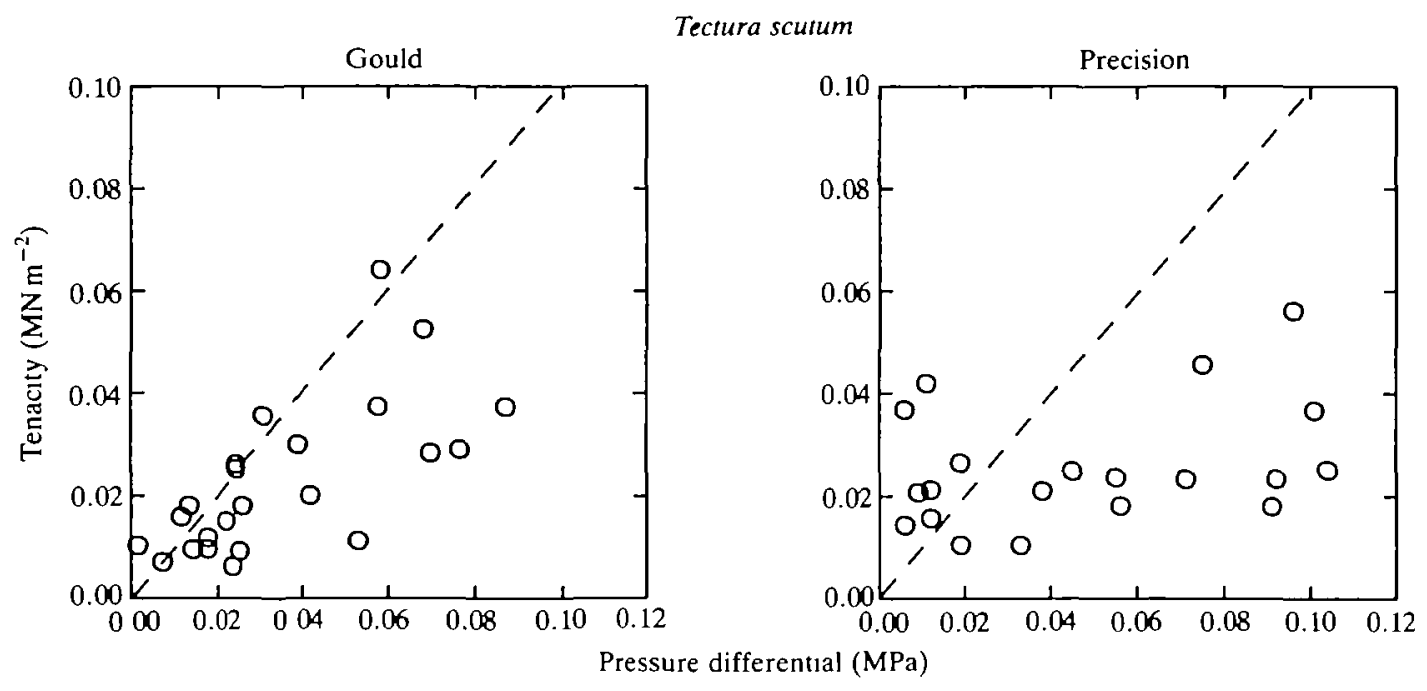

Fig. 4. Pressure differential versus tenacity for Tectura scutum. Data for the Gould and the Precision transducers are shown. The dashed lines are drawn where $\Delta P=T$. For points above the line, the absolute value of the pressure differential is not high enough to account for the tenacity. All points on or below the line can be accounted for by a suction mechanism.

detaching force per unit area reaches the maximum that can be supported by the pressure differential.

In almost all of the trials with the Gould transducer, the pressure differential accounted for all of the limpet's tenacity. Fig. 3B,C shows examples of simultaneous force and pressure measurements. In Fig. 3B the maximum pressure differential is $0.030 \mathrm{MPa}$, and the tenacity is $0.009 \mathrm{MN} \mathrm{m}^{-2}$. In Fig. $3 \mathrm{C}$ the maximum pressure differential is $0.022 \mathrm{MPa}$, and the tenacity is $0.015 \mathrm{MN} \mathrm{m}^{-2}$.

Figs 4 and 5 show graphs of $\Delta P$ versus $T$ for $T$. scutum and $L$. gigantea. The dashed line on each graph corresponds to $\Delta P / T=1$. Points on or below the line indicate that the pressure differential is equal to or greater than the tenacity, as predicted for a suction mechanism. Points above the line indicate that the pressure differential is less than the tenacity, and other mechanisms must act in addition to suction to account for the excess tenacity. Most of the points fall below or close to the line, supporting a suction mechanism. In only one trial with the Gould transducer was it clear that the limpet was using glue. In this case the tenacity was greater than $0.05 \mathrm{MN} \mathrm{m}^{-2}$ and there was almost no pressure differential.

Throughout the course of each trial, the force per unit area acting to detach the limpet sometimes temporarily exceeded the pressure differential. Including these cases, the force per unit area exceeded the pressure differential at some point in $36 \%$ of the trials with the Gould transducer. The mean discrepancy was $0.018 \pm 0.015 \mathrm{MPa}(N=21)$. This includes two limpets that were not centred over the transducer, so the transducer may initially have been under the area of the 


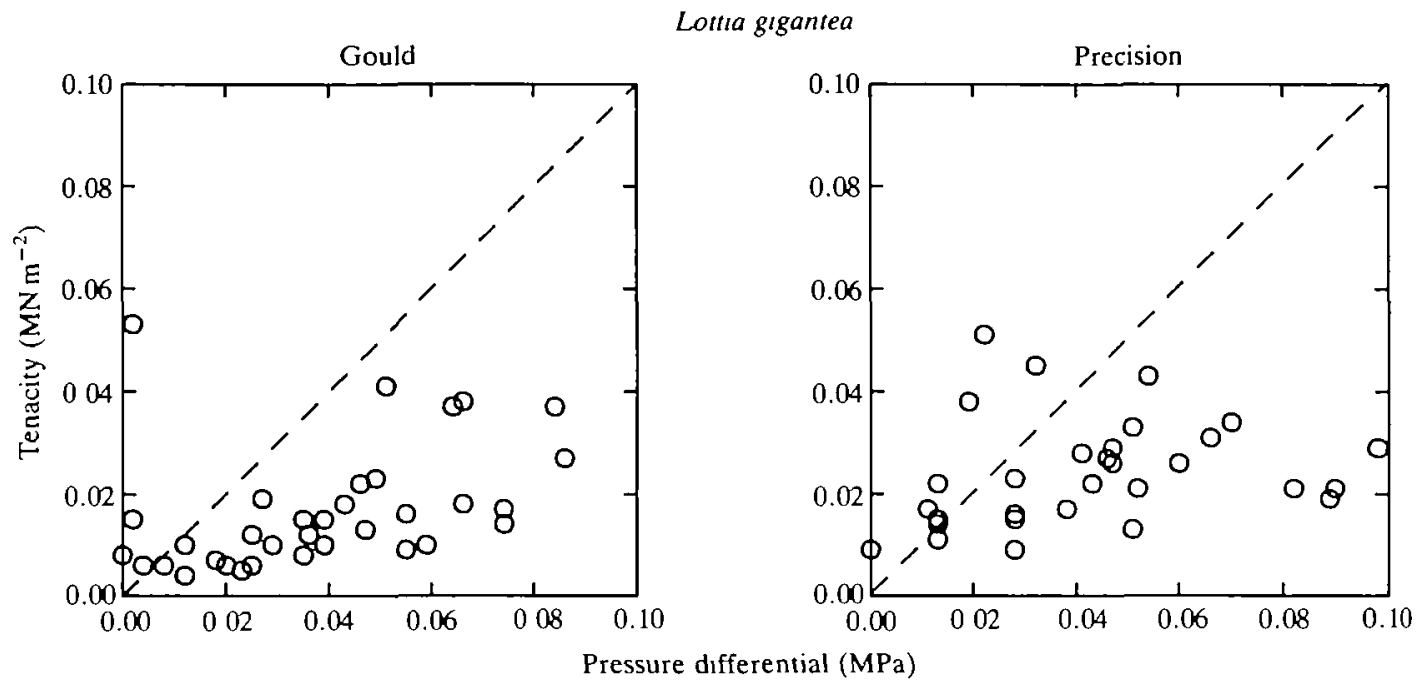

Fig. 5. Pressure differential versus tenacity for Lottia gigantea. Data for the Gould and the Precision transducers are shown. The dotted lines are drawn where $\Delta P=T$. For points above the line, the absolute value of the pressure differential is not high enough to account for the tenacity. All points on or below the line can be accounted for by a suction mechanism.

margin that formed the seal. Thus, it would not sense any pressure decrease until immediately before detachment. The majority of the recorded discrepancies occurred when the detaching force was first applied, typically producing a force per unit area of approximately $0.015 \mathrm{MN} \mathrm{m}^{-2}$ with almost no corresponding pressure differential. As the force per unit area increased further, the pressure decreased to match it.

Similarly, in $36 \%$ of the trials with the Precision transducer, at some point the tenacity exceeded the pressure differential. The mean discrepancy in these cases was $0.019 \pm 0.015 \mathrm{MPa}(N=19)$.

Relative to the remotely mounted Gould transducer, the Precision transducer, which was flush with the substratum, did not measure any excess pressure drop at a given tenacity. For T. scutum attached over the Gould transducer, the mean value of $\Delta P / T$ was $1.69 \pm 1.05(N=23)$. Using the Precision transducer, $\Delta P / T$ was $1.99 \pm 1.44(N=21)$. There was no significant difference between these two means ( $t$-test, $P=0.44)$. For $L$. gigantea attached over the Gould transducer, the mean value of $\Delta P / T$ was $2.76 \pm 1.55(N=35)$, and using the Precision transducer, $\Delta P / T$ was $1.90 \pm 1.18(N=32)$. The difference between these means is statistically significant ( $t$-test, $P=0.014)$.

For comparison, Fig. 6 shows the predicted area of the foot exposed to decreased pressure, based on values of $\Delta P / T$ in the observed range. The outline of the foot is based on typical proportions for $T$. scutum. This figure gives a rough idea of the relative area of the margin that is predicted to be pressed down to form 

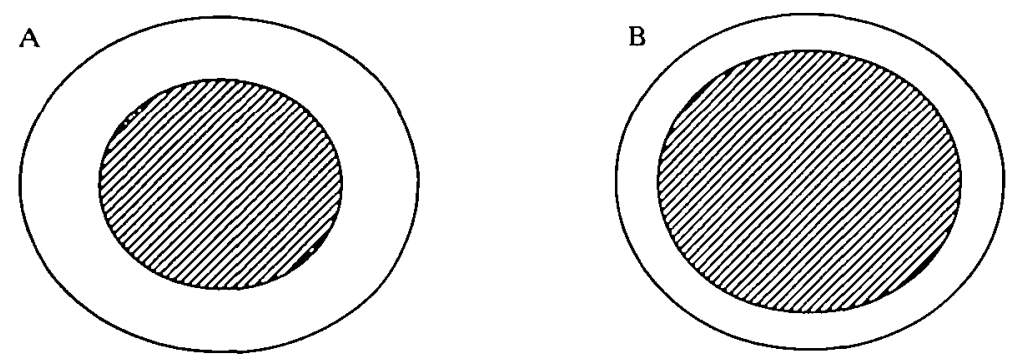

Fig. 6. Estimates of the area that must be exposed to reduced pressure to account for different values of $\Delta P / T$. (A) $\Delta P / T=2.7$. (B) $\Delta P / T=1.7$. The unshaded area represents the margin, which is pressed against the substratum.

a seal. In many of the videos of limpet detachment, one can see the faint outline of the area of the foot margin that is presumably pressed down, and it is typically of the same magnitude as that predicted in Fig. 6. Morphological studies (S. Johnsen, unpublished results) also show a distinct region, lacking muscle fibres and filled with connective tissue, at the margin of the foot. This area is similar to but slightly smaller than the area expected from Fig. 6.

\section{Effect of decreased ambient pressure on limpet attachment}

As previously stated, the Precision transducer measures the combined effect of hydrostatic pressure decrease and stress transmitted by any glue present. In effect, it provides a local measurement of the force per unit area of attachment. As predicted for a suction mechanism, the force per unit area measured in this way was dependent on ambient pressure (linear regression, $P<0.0005$, Fig. 7 ). It was apparent during the experiments that the force per unit area measured locally by the Precision transducer corresponded well to the total attachment force. At ambient pressures of approximately $0.01 \mathrm{MPa}$, the total attachment force perceived by the experimenter was negligible.

The maximum possible pressure differential that a sucker can generate on silicone at a given ambient pressure is indicated by the dashed line in Fig. 7. In only three of 42 trials did the limpet's attachment force per unit area exceed the maximum value predicted for a sucker at that pressure. In the most extreme case the force per unit area was only $0.017 \mathrm{MPa}$ beyond this limit.

The control experiments showed that physiological stress from exposure to a partial vacuum does not weaken limpet attachment. At atmospheric pressure, the mean attachment force per unit area measured by the Precision transducer was $0.044 \pm 0.013 \mathrm{MPa}(N=10)$. If the ambient pressure was first decreased to between 0.03 and $0.01 \mathrm{MPa}$ for $20 \mathrm{~s}$, and the limpet was returned to atmospheric pressure and immediately detached (within $5 \mathrm{~s}$ ), the mean attachment force per unit area was $0.047 \pm 0.025 \mathrm{MPa}(N=10)$. There was no significant difference between these means $(t$-test, $P=0.81)$. 


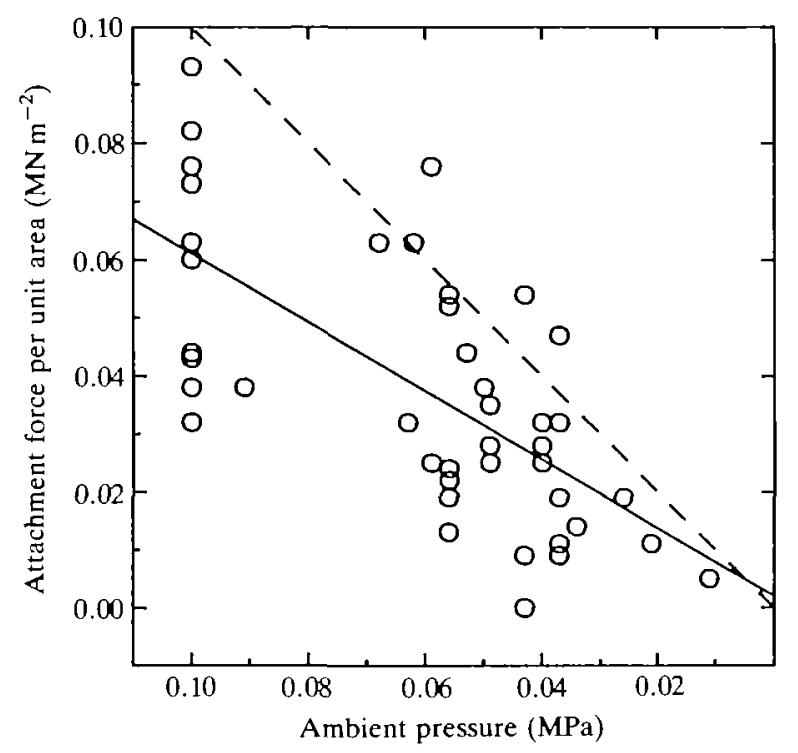

Fig. 7. Experiments performed on Lottia gigantea in a bell jar to determine the effect of ambient pressure on attachment force. Attachment force per unit area measured by the Precision transducer is plotted against the ambient pressure in the chamber. The solid line is a linear regression of the data $(y=0.59 x+0.002 ; r=0.68 ; P<0.0005)$. The dashed line shows where the combined decrease in ambient pressure and the attachment force per unit area of the limpet add up to $0.1 \mathrm{MPa}$. If the limpets use suction, then the points will fall on or below this line.

\section{Discussion}

The data from the limpets studied in this report show that they use a suction attachment mechanism. Observations of the effect of leaks on limpet attachment and analysis of videotapes of limpets being detached support this conclusion. Also, limpets actively decrease the pressure under their feet. This pressure decrease can account for all of their tenacity for up to an hour after their initial attachment, in most of the individuals studied. Finally, their attachment force per unit area depends on ambient pressure.

In addition, limpets use some form of glue in attachment. This glue can generate weak bonds that may help initiate suction attachment. For suction to work, the edge of the foot must be sealed to the substratum (Kier and Smith, 1990); glue may help the animal to adhere while it establishes a seal. A glue may also help to maintain a seal around the edge of their feet. This may be particularly important on a non-homogeneous or irregular substratum.

Glue also appears to be used for stronger, more long-lasting attachments. If limpets are left undisturbed overnight, approximately one-third of them will form this type of attachment to the substratum in the laboratory. It should be remphasized, however, that it is still not certain that the tenacity in these cases is due to glue alone. 


\section{The mechanism of attachment in the field}

Denny et al. (1985) note that limpets are often tightly clamped down at low tide, whereas they move around to browse at high tide when wave forces are at their strongest. The recognition that limpets can use either suction or glue suggests that, over the course of a day, limpets may alternate between the two attachment mechanisms. When the tide is low and they are exposed, they may glue themselves down to avoid desiccation and predation by birds. In this way, they can maintain a strong attachment at little metabolic cost. Then, when the tide rises, they can release that attachment to move around and forage. During wave surges or when they are threatened, they may use suction to generate strong, temporary attachments.

The presence of two distinct attachment mechanisms may explain the observation that limpets' tenacities differ depending on whether they have been moving recently. Denny et al. (1985), Branch and Marsh (1978) and Miller (1974) all report different tenacities for moving and stationary limpets. Denny et al. (1985) measured the tenacity of $T$. scutum (formerly Notoacmea scutum) in the field and calculated a mean tenacity of $0.058 \pm 0.041 \mathrm{MN} \mathrm{m}^{-2}(N=30)$ for limpets that had been moving immediately before the test and a tenacity of $0.173 \pm 0.079 \mathrm{MN} \mathrm{m}^{-2}$ $(N=30)$ for limpets that were stationary before the test. A tenacity of $0.173 \mathrm{MN} \mathrm{m}^{-2}$ is within the range expected for a glue. In contrast, $0.058 \mathrm{MN} \mathrm{m}^{-2}$ is lower than expected for suction adhesion, but still consistent with that mechanism.

\section{Do suction and glueing work additively?}

Because limpets can use both suction adhesion and glue, it is possible that the glue can be used to supplement the attachment force generated by suction. Experiments conducted at reduced ambient pressure, however, show that, for at least an hour after moving, limpets use suction alone as their primary attachment mechanism. Simultaneous tenacity and pressure measurements lead to the same conclusion.

Comparison of the tenacity and pressure measurements using the two different transducers also shows that suction and glue do not work additively. The mean value of $\Delta P / T$ measured by the Precision transducer is either not significantly different (T. scutum) or it is significantly less (L. gigantea) than the mean value of $\Delta P / T$ measured by the Gould transducer. This means that, for a given tenacity, the Precision transducer typically measures a similar or smaller pressure differential than the Gould transducer. If the Precision transducer measured a greater pressure differential, it would indicate that a solid glue was providing some of the adhesive force in addition to suction. The lower mean value measured by the Precision transducer makes the possibility of a glue acting simultaneously with suction unlikely on this surface.

It is possible that glue may work with suction at low tenacities. Of the instances where the force per unit area exceeded the pressure differential measured by the Gould transducer, the majority occurred when the detaching force was first 
applied. The excess was typically between 0.01 and $0.02 \mathrm{MPa}$, suggesting the presence of a weak adhesive acting initially in addition to suction. Nevertheless, discrepancies of a similar magnitude occurred as frequently with the Precision transducer as with the Gould. Therefore, these discrepancies are more likely to be due to causes other than the presence of glue.

\section{Analysis of the pressure data}

There are several factors affecting the interpretation of the pressure transducer data. The most important is that the tenacities of limpets attached to the pressure transducers were considerably lower than those measured on smooth glass or acrylic surfaces. This is primarily due to the effect of the pressure transducers themselves. Both had hydrophobic areas that nucleate cavitation at $0 \mathrm{MPa}$. Thus, the limpet's tenacity would be limited to less than $0.1 \mathrm{MN} \mathrm{m}^{-2}$. In fact, since the magnitude of the pressure differential was shown to be on average approximately twice the tenacity, cavitation at $0 \mathrm{MPa}$ could limit the tenacity to well below $0.1 \mathrm{MN} \mathrm{m}^{-2}$. The compliance of the Gould transducer may also have contributed to the lower tenacities. The tubing leading to the Gould transducer is not completely rigid and there is a significant volume of water within the transducer head and tubing. A decrease in pressure may cause slight collapse of the tubing, so that water may be displaced from the transducer system to the space under the limpet's foot. Limpets maintain an extremely small volume under their feet and the displacement of water from the transducer may cause failure of their attachment due to leaks. Thus, neither of the transducers promoted a high tenacity. Not surprisingly, it was clear from the limpets' behaviour that the pressure transducers were not a preferred substratum. This made it necessary to build walls on the transducer platform to keep the limpets from moving away from the transducer.

The compliance of the Gould transducer may also have affected the measurements of $\Delta P / T$. In some trials, the compliance of the transducer may cause leak formation before the detaching force reaches the force that the pressure differential can sustain. Thus, the magnitude of the pressure differential would be well in excess of the tenacity. Also, when the pressure changes suddenly, limitations of the Gould transducer's frequency response may lead to an overestimate of the pressure drop (Gabe, 1972). Nevertheless, one can estimate the maximum error due to the frequency response by looking at the overshoot from a step change in pressure, and the corrected pressure differentials still account for the tenacity. These effects may, however, explain why $\Delta P / T$ measured by the Gould transducer was significantly higher than $\Delta P / T$ measured by the Precision transducer for L. gigantea.

Another potential source of error arose from the difficulty of centring the limpet over the transducers. This was more of a factor with the Precision transducer, and may explain those trials with the Precision transducer where $\Delta P / T$ was less than 1 . The transducer may have been near or partially under the area at the margin of the foot that was pressed down to form a seal. The resulting positive pressure would 
cancel some of the decrease in hydrostatic pressure, resulting in lower output. Also, because the Precision transducer is glued into the surface, the margin may not need to press directly on the transducer to decrease its output. Bending of the surface near the transducer affects the output of the Precision transducer.

The effect of the margin is particularly clear in one case, in which the pressure under the limpet's foot increased slightly above ambient pressure as the detaching force was applied (Fig. 2D). Immediately before removal, the pressure suddenly decreased. The positive pressure may have been measured because the transducer was under the foot margin. The sudden decrease in pressure may have occurred as the sole of the foot was lifted away, from the centre out, uncovering the transducer.

One interesting result from the pressure measurements was the shape of the pressure traces. The fact that the pressure often stayed constant for extended periods suggests the presence of catch muscle. L. Gamez (unpublished results) has also suggested that the shell-foot retractor of $L$. gigantea contains catch muscle. This conclusion was based on changes in the muscle's isometric tension in separate bathing solutions of acetylcholine and 5-hydroxytryptamine. The reason that the steplike pressure traces are more commonly seen using the Gould transducer is unknown, but may also be due to the compliance of the Gould transducer.

\section{Stefan adhesion}

Although it has been proposed that limpets might use Stefan adhesion, the evidence in this paper does not support that hypothesis. The effect of leaks on limpet attachment argues against a role for Stefan adhesion. The presence of a leak will rapidly equalize the pressure differential created by a sucker, eliminating its attachment force. If a limpet is glued to the substratum, then a leak may weaken the glue, but it will not eliminate the attachment force. Similarly, a limpet relying on Stefan adhesion will not be greatly affected by the introduction of small leaks. In Stefan adhesion, the two adhering surfaces are so closely apposed that viscosity resists the flow of the intervening fluid that must accompany separation of the surfaces (see Denny, 1988). Thus, in Stefan adhesion, water or air will flow under the foot from the foot's edge as separation from the substratum increases; introducing yet another avenue for fluid to leak under the foot will not speed up the separation appreciably.

Video analysis also provides evidence that limpets do not use Stefan adhesion. The dominant mode of attachment failure is through a localized break in the seal at the margin of the foot. A limpet foot relying on Stefan adhesion would not fail in this manner. The videos also provide evidence for sudden failure caused by cavitation of the fluid under the foot. Grenon and Walker (1981) point out that cavitation will decrease the tenacity of a Stefan adhesive. Nevertheless, cavitation will not suddenly eliminate adhesion. This is because as a gas bubble is created, it must still expand to cause adhesive failure. This expansion is resisted by the remainder of the foot area which is still attached. The situation is analogous to the introduction of a leak under the foot, which was described previously. 
The constant, sustained pressure differentials maintained by many limpets are also difficult to reconcile with a Stefan adhesion mechanism. The tenacity of a Stefan adhesive is proportional to the strain rate, so that, for light forces sustained over time, it provides little adhesion (Denny, 1988). A limpet using Stefan adhesion to pull its shell down against the substratum would experience a decay in tenacity with time as fluid slowly filled the volume underneath the animal's foot.

Tenacity measurements on limpets provide even stronger evidence against Stefan adhesion. The equations for Stefan adhesion presented by Grenon and Walker (1981) and Denny (1988) show that the attachment force of a Stefan adhesive is proportional to the fourth power of the foot radius. Thus, the attachment force should be proportional to the square of the foot area. The attachment force is actually linearly proportional to the foot area, as predicted for a suction mechanism. In this study, force was proportional to area ${ }^{0.85}$. This is in agreement with Grenon and Walker's data for Patella vulgata (Grenon and Walker, 1981). Combining their data, we can calculate that force is proportional to area $^{1.07}(N=228)$. Also, the tenacity of a Stefan adhesive should be linearly proportional to the speed of detachment of the limpet (Grenon and Walker, 1981). Grenon and Walker measured limpet tenacity relative to the rate of separation between the shell and the substratum. These data show an initial increase in tenacity with increasing separation rate, then a consistent decrease. At the higher separation rates the tenacity is lower than or equal to the tenacity at the lowest separation rate.

Grenon and Walker's (1981) data for $P$. vulgata are consistent with a suction mechanism. Suction attachment depends on the wettability of the surface (Smith, 1991), and the tenacities of limpets studied by Grenon and Walker (1981) were dependent on surface wettability. Also, the tenacities of limpets on a non-wettable Teflon surface were $0.079 \pm 0.022$ and $0.097 \pm 0.004 \mathrm{MN} \mathrm{m}^{-2}$ in separate experiments (Grenon and Walker, 1981). Since seawater cavitates at $0.009 \pm 0.006 \mathrm{MPa}$ on non-wettable surfaces (Smith, 1991), suckers should have a maximum tenacity on Teflon of anywhere from 0.05 to $0.1 \mathrm{MN} \mathrm{m}^{-2}$, depending on the size of the margin.

Some of the support for a Stefan-based adhesive mechanism in limpets comes from theoretical estimates of the attachment force that can be achieved with such a mechanism. These estimates are certainly an overestimate of the possible tenacity. The equation for the force derived from Stefan adhesion assumes that both surfaces are rigid flat plates. Deviations from this assumption are likely to cause considerable errors. Thus, the equations are probably not relevant to limpet feet, which are far from perfectly rigid.

\section{The nature of limpet glue}

It has often been suggested that limpets use mucus as a glue (see Grenon and Walker, 1980, 1981). Denny and Gosline (1980) demonstrated the viscoelastic properties of the pedal mucus of slugs, and Denny (1980) showed how these properties can be used in locomotion. The maximum shear stress that slug mucus 
can sustain elastically ranges from 0.0004 to $0.002 \mathrm{MN} \mathrm{m}^{-2}$, depending on strain rate and strain (Denny and Gosline, 1980). Limpet tenacities typically range from 0.1 to $0.3 \mathrm{MN} \mathrm{m}^{-2}$ at a comparable strain rate (Grenon and Walker, 1981). Although shear strength and tensile strength are different, they should be of the same order of magnitude for elastic materials. For an incompressible fluid, the shear modulus is one-third of the elastic modulus (Wainwright et al. 1976). Assuming that the breaking strain in tension is similar to the breaking strain in shear, the tensile strength should be approximately three times the shear strength. This is still orders of magnitude too low to account for limpet tenacity. Also, Denny (1984) calculated an estimated work of fracture for mucus in tension and concluded that it can only account for a fraction of the energy needed to detach a limpet. Limpet mucus by itself is not noticeably sticky and mucus may even function as a de-adhesive for some animals (Hermans, 1983; Thomas and Hermans, 1985). The tenacities measured for limpets are, however, in the range of the tensile strength of seawater, which can sustain absolute pressures ranging from 0 to $-0.7 \mathrm{MPa}$, depending on the surfaces used (Smith, 1991). When limpets do use glue for long-term adhesion, they leave behind a patch of material that is markedly stiffer than the pedal mucus they normally secrete.

Although mucus alone is probably not a strong adhesive, there may be other compounds involved in limpet attachment. The stickiness observed during initial adhesion can appear and disappear rapidly, suggesting that it may be based on a secretion. The glue that functions in longer-term adhesion seems to take longer to set but may still be related to this stickiness. A secretion distinct from mucus could be a glue, or it could act as a tanning agent or catalyst to solidify the pedal mucus. Denny and Gosline (1980) noted that addition of calcium stiffens gastropod pedal mucus.

The recognition that limpets use a suction attachment mechanism, and that this may account for their adhesion when they are most vulnerable to wave surge, is a significant change in our understanding of limpet attachment. There are interesting functional consequences associated with suction adhesion that should be investigated (see Smith, 1991). It will also be interesting to see if other gastropods alternate between suction and glueing. In view of this, future studies of gastropod tenacity must make clear whether the animal is using suction or glue at the time of the test. Finally, it is clear that the role of suction in nature has been underestimated. The experiments described in this paper should provide a useful methodology for discriminating between suction, Stefan adhesion and glueing in future work.

I would like to thank W. M. Kier for thoughtful discussions and technical help throughout this research. I would also like to thank W. M. Kier and M. W. Denny for helpful comments on this manuscript. I thank D. Pentcheff and B. Holthuis for the time they spent collecting limpets for me. This material is based on work supported by a National Science Foundation Graduate Fellowship and a National 
Science Foundation Presidential Young Investigator Award (DCB-8658069) to W. M. Kier.

\section{References}

Aubin, P. A. (1892). The limpet's power of adhesion. Nature 45, 464-465.

Branch, G. M. and Marsh, A. C. (1978). Tenacity and shell shape in six Patella species: adaptive features. J. exp. mar. Biol. Ecol. 34, 111-130.

CRISP, D. J. (1973). Mechanisms of adhesion of fouling organisms. In Proceedings of the 3rd International Congress on Marine Corrosion and Fouling in the Sea, Gaithersburg, 1972 (ed. R. F. Acker, B. F. Brown, J. R. DePalma and W. P. Iverson), pp. 691-709. Gaithersburg, Maryland: National Bureau of Standards.

Davis, J. R. A. (1895). The habits of limpets. Nature 51, 511-512.

Denny, M. W. (1980). The role of gastropod pedal mucus in locomotion. Nature 285, 160-161.

DenNy, M. W. (1984). Mechanical properties of pedal mucus and their consequences for gastropod structure and performance. Am. Zool. 24, 23-36.

Denny, M. W. (1988). Biology and the Mechanics of the Wave-swept Environment. Princeton: Princeton University Press.

Denny, M. W., Daniel, T. L. And Koehl, M. A. R. (1985). Mechanical limits to size in waveswept organisms. Ecol. Monogr. 55, 69-102.

Denny, M. W. And Gosline, J. M. (1980). The physical properties of the pedal mucus of the terrestrial slug Ariolimax columbianus. J. exp. Biol. 88, 375-393.

GABE, I. T. (1972). Pressure measurement in experimental physiology. In Cardiovascular Fluid Dynamics (ed. D. H. Bergel), pp. 11-50. London: Academic Press.

Grenon, J. F. AND WALKER, G. (1980). Biomechanical and rheological properties of the pedal mucus of the limpet, Patella vulgata L. Comp. Biochem. Physiol. B 66, 451-458.

Grenon, J. F. AND Walker, G. (1981). The tenacity of the limpet, Patella vulgata L.: an experimental approach. J. exp. mar. Bıol. Ecol. 54, 277-308.

Hermans, C. O. (1983). The duo-gland adhesive system. Oceanogr. mar. Biol. A. Rev. 21, 283-339.

KIER, W. M. AND SMITH, A. M. (1990). The morphology and mechanics of octopus suckers. Biol. Bull. mar. biol. Lab., Woods Hole 178, 126-136.

LindBerG, D. L. (1986). Name changes in the 'Acmaeidae'. Veliger 29, 142-148.

Loppens, K. (1922). Note sur la variabilité et l'ethologie de Patella vulgata. Ann. Soc. R. Zool. Malac. Belg. 53, 57-68.

Menke, H. (1911). Physikalische und physiologische Faktoren bei der Anheftung von Schnecken der Brandungszone. Zool. Anz. 37, 19-30.

Miller, S. L. (1974). Adaptive design of locomotion and foot form in prosobranch gastropods. J. exp. mar. Biol. Ecol. 14, 99-156.

Parker, G. H. (1911). The mechanism of locomotion in gastropods. J. Morph. 22, 155-170.

Pí́ron, H. (1909). Contribution à la biologie de la Patelle et de la Calyptrée. Bull. Biol. Fr. Belg. 43, 183-202.

Smith, A. M. (1991). Negative pressure generated by octopus suckers: a study of the tensile strength of water in nature. J. exp. Biol. 157, 257-271.

Thomas, I. M. (1948). The adhesion of limpets. Austr. J. Sci. 2, 28-29.

Thomas, L. A. and Hermans, C. O. (1985). Adhesive interactions between the tube feet of a starfish, Leptasterias hexactis, and substrata. Biol. Bull. mar. biol. Lab., Woods Fole 169, $675-688$.

Wainwright, S. A., Biggs, W. D., Currey, J. D. and Gosline, J. M. (1976). Mechanical Design in Organisms. New York: John Wiley \& Sons.

WELLS, M. M. (1917). The behavior of limpets with particular reference to the homing instinct. J. Anim. Behavior 7, 387-395.

Yule, A. B. AND CRISP, D. J. (1983). Adhesion of cypris larvae of the barnacle, Balanus balanoides, to clean and arthropodin treated surfaces. J. mar. biol. Ass. U. K. 63, 261-272. 